\title{
VARIOUS PRESENTATIONS OF TRAUMATIC DIAPHRAGMATIC HERNIA- A CASE SERIES
}

\author{
Mahalakshmi Ashok Kumar1, Manimaran Thangavelu², Villalan Ramasamy33, Rajeswari Appanamuthu Mari ${ }^{4}$, Anandan Kanthan ${ }^{5}$
}

1Assistant Professor, Department of General Surgery, KAPV Government Medical College, Trichy, Tamilnadu, India. ${ }_{2}^{2}$ Assistant Professor, Department of General Surgery, KAPV Government Medical College, Trichy, Tamilnadu, India. ${ }_{3}^{3}$ Assistant Professor, Department of General Surgery, KAPV Government Medical College, Trichy, Tamilnadu, India. 4Postgraduate Student, Department of General Surgery, KAPV Government Medical College, Trichy, Tamilnadu, India. ${ }_{5}^{5}$ Assistant Professor, Department of General Surgery, KAPV Government Medical College, Trichy, Tamilnadu, India.

ABSTRACT
BACKGROUND
Abstract traumatic diaphragmatic hernias can be caused by both severe blunt trauma as well as penetrating trauma with an
incidence of $2-6 \%{ }^{(1)}$. They may have a mortality rate of upto $31 \%$ according to a recent study.(2) Sometimes traumatic
diaphragmatic rupture may go unnoticed and often there is a delay between injury and diagnosis. Few cases have presented
decades later after injury.(2) This article is a case report of variable presentation of traumatic diaphragmatic rupture that we
encountered during last year. The first one was a bull gore injury that presented with acute breathlessness with a penetrating
injury on (L) lower chest at the time of admission. Second one was a case of RTA with no evidence of chest and abdominal injury on
admission. But one week later, he became dyspnoeic and on evaluation, he was found to have (L) diaphragmatic rupture with
herniation of bowel into thoracic cavity through radiological findings. Third one was a two-year-old stab injury who presented to
us with a history of non-specific abdominal pain on and off and was presenting with features of intestinal obstruction and was
diagnosed as a delayed presentation of traumatic diaphragmatic hernia.

\section{KEY WORDS}

Diaphragmatic Hernia, Trauma.

HOW TO CITE THIS ARTICLE: Kumar MA, Thangavelu M, Ramasamy V, et al. Various presentation of traumatic diaphragmatic hernia- a case series. J. Evolution Med. Dent. Sci. 2018;7(38):4249-4251, DOI: 10.14260/jemds/2018/948

\section{CASE REPORT 1}

40 years old male admitted with history of bull gore injury with penetrating chest injury. He had laceration over (L) lower chest region, through which food particles were spilling and was in ventilatory failure. His vitals were unstable. He was started on mechanical ventilation and his CT Chest showed diaphragmatic rupture with herniation of bowel into thoracic cavity. He was proceeded with emergency laparotomy. On exploration, there was $10 \mathrm{cms}$ defect in (L) the dome of diaphragm (Fig. 2) and $8 \mathrm{cms}$ linear defect in lower end of oesophagus along with herniation of stomach, omentum into (L) Hemithorax. After reduction of contents, diaphragmatic defect is closed with one prolene in 2 layers and oesophageal defect is closed in 2 layers with Vicryl and silk. (L) Chest drain was inserted. Patient was stable postoperatively and ICD removal was done on $8^{\text {th }}$ POD. Suture removal was done on $15^{\text {th }}$ POD. Patient recovered well.

\section{CASE REPORT 2}

30 years male presented with history of breathlessness after 1-week-old trauma from RTA associated (L) humerus and (L) acetabular \#. He did not have any chest or abdominal symptoms at the time of injury. CXR taken at the time of

'Financial or Other Competing Interest': None.

Submission 04-08-2018, Peer Review 01-09-2018,

Acceptance 06-09-2018, Published 17-09-2018.

Corresponding Author:

Manimaran Thangavelu,

Assistant Professor,

Department of General Surgery,

KAPV Government Medical College,

Trichy, Tamilnadu, India.

E-mail: rajieinraja@gmail.com

DOI: $10.14260 /$ jemds $/ 2018 / 948$

(c) $(1)$

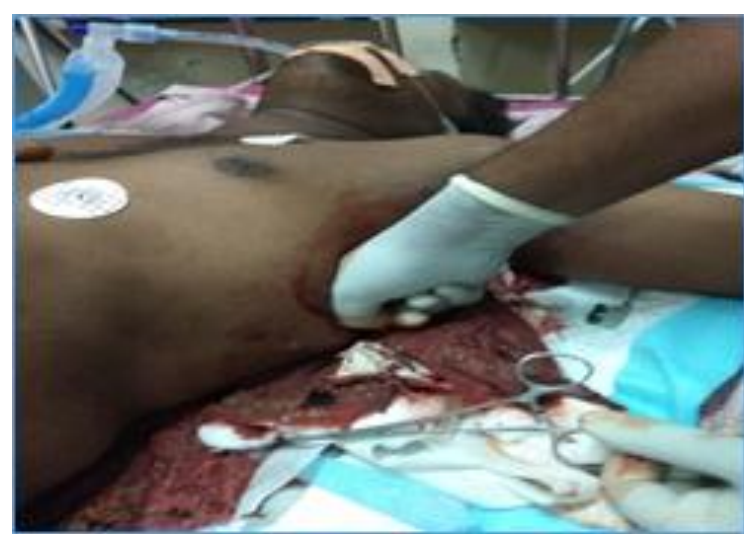

Figure 1. Presentation of case 1 on admission at ER

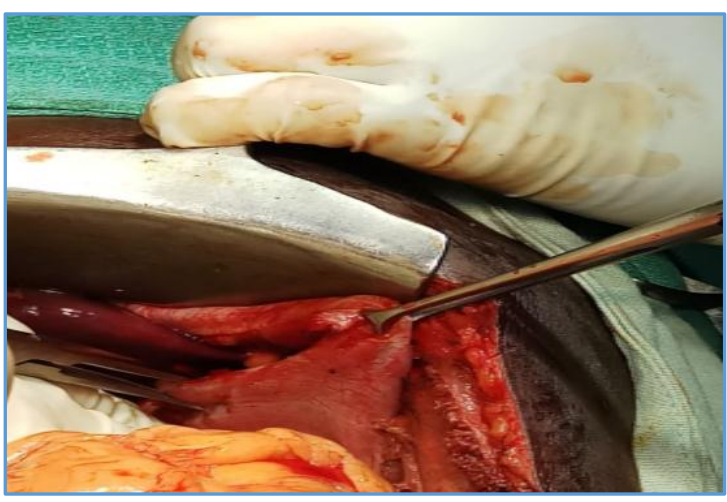

Figure 2. Intra op image of case1 $10 \mathrm{~cm}$ defect in Left dome diaphragm

admission was normal. No evidence of obstruction or gangrene formation. He gradually developed chest symptoms for which he was evaluated with CXR again (Fig. 3) also with 
CT chest which showed diaphragmatic rupture with herniation of bowel into (L) Hemithorax (Fig. 4). He was haemodynamically stable. Baseline investigations were inconclusive. Clinical examination had decreased air entry over left chest, except which was normal. Therefore, after confirmation with radiological finding of delayed traumatic diaphragmatic hernia, he was proceeded with Laparotomy through rooftop abdominal incision. And he had diaphragmatic rupture of (L) dome of diaphragm to around $10 \mathrm{cms}$ with herniation of (L) lobe of liver, stomach, spleen, omentum, transverse colon causing mediastinal shift to (R) side with passive collapse of (L) lung. Reduction of herniated contents is done slowly and after reposition diaphragmatic rupture was repaired in 2 layers with 1 prolene. Chest drain was kept.(3) The patient remained stable post-operatively. ICD removal was done on $9^{\text {th }}$ POD. Suture removal done on $16^{\text {th }}$ POD. Patient recovered well.

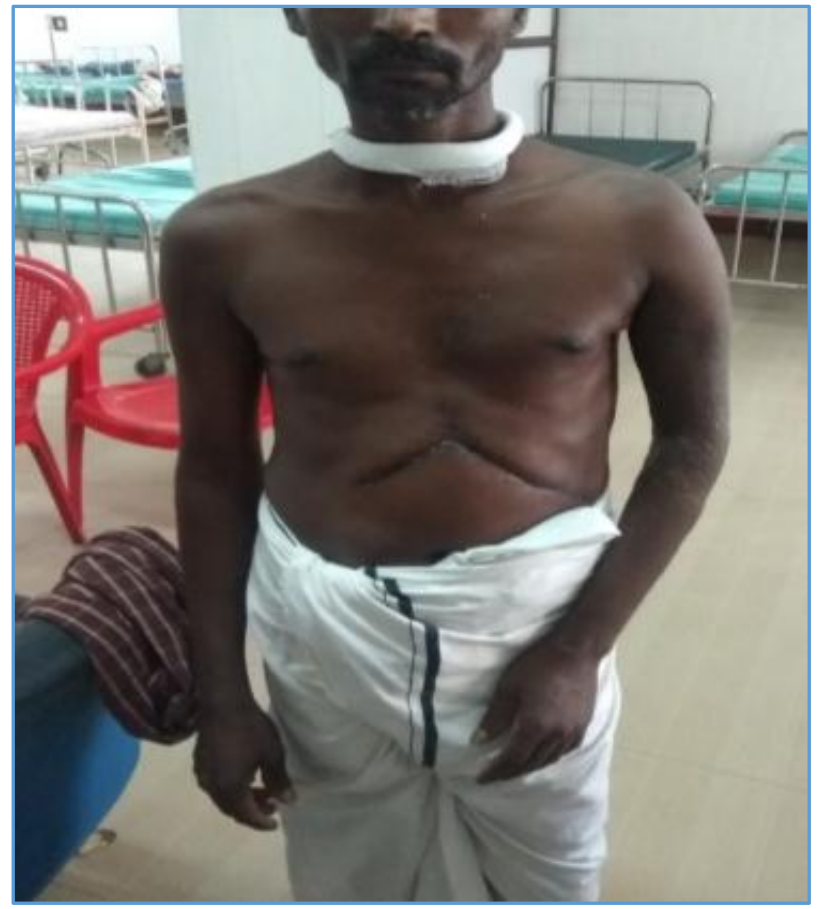

Figure 3. Post-Operative picture of case 2

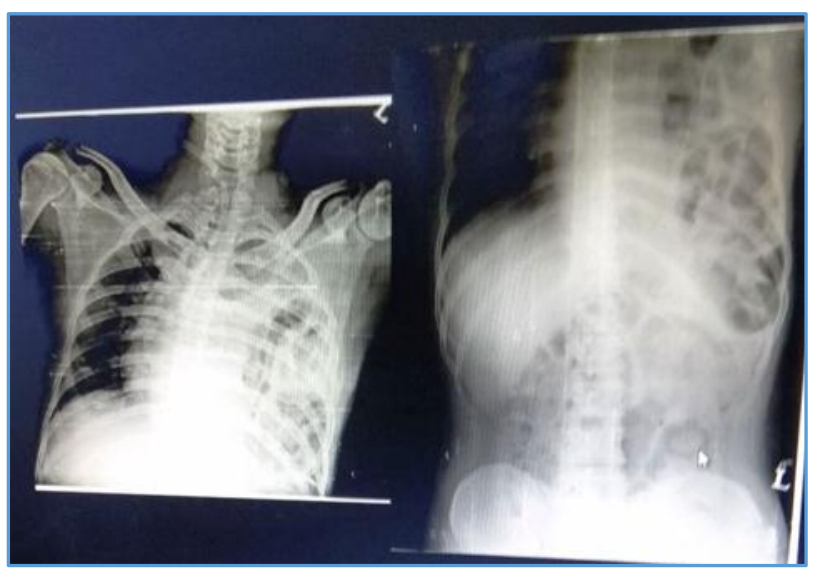

Figure 4. Chest xray of case 2 at presentation and after one week

\section{CASE REPORT 3}

22 years male was admitted with history of non-specific abdominal pain with previous history of penetration (L), lower chest stab injury. On examination, his general condition was good. Vitals were stable. Sp02 was $95 \%$ with RA. CVS S1 S2 (+), RS B/L (+). On abdominal examination, he had tenderness over all the quadrants with guarding with rigidity and bowel sound was absent. He was evaluated radiologically and his chest X-ray and CT chest (Fig. 6) showed herniation of bowel loops into (L) hemithorax. Patient underwent Laparotomy with (L) thoracotomy and he had a defect of 6 $\mathrm{cm}$ over (L) dome of diaphragm with gangrenous stomach into (L) hemithorax with collapsed (L) lung. Gastrectomy with oesophagojejunostomy with feeding jejunostomy done. Diaphragmatic rent was closed in 2 layers with 1 prolene. (L) Side chest drain was kept. Post-operatively, patient recovered well. ICD removal was done on $5^{\text {th }}$ POD. Suture removal was done on $12^{\text {th }}$ POD.

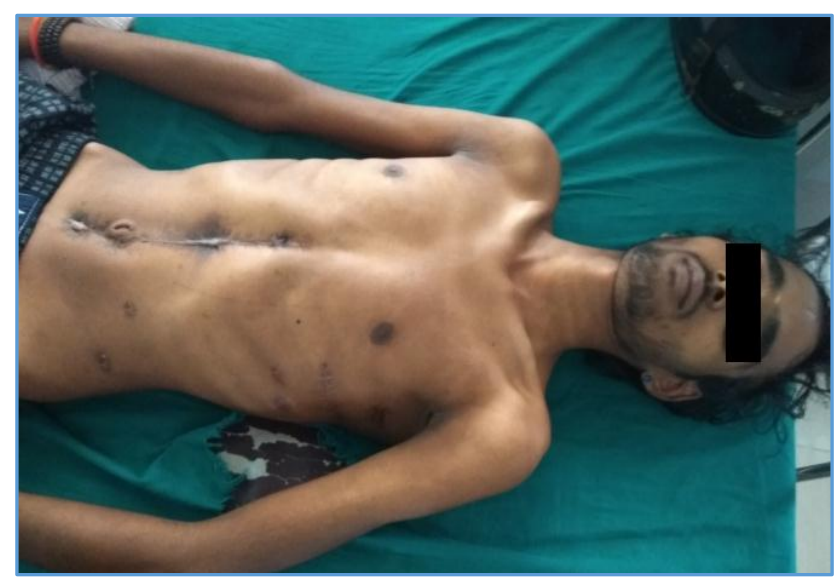

Figure 5. Post op Pic of Case 3

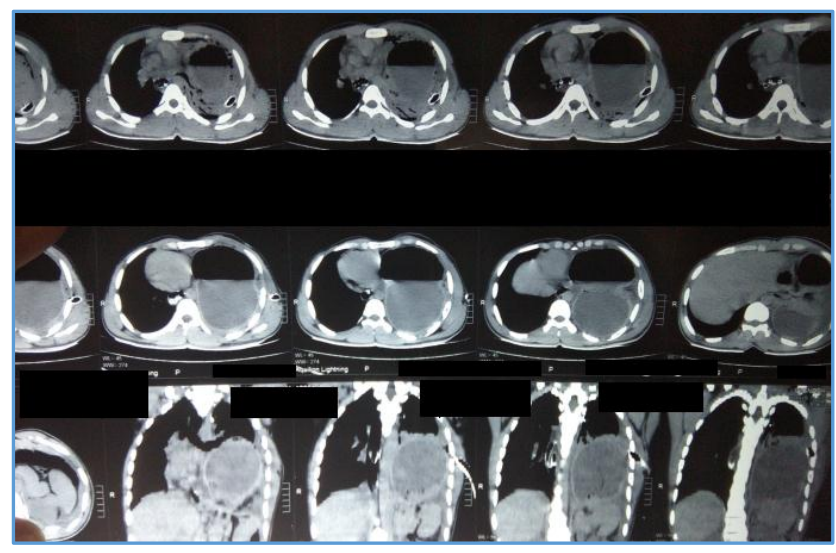

Figure 6. CT chest of case 2 - Herniation of Bowel into Left Hemithorax

\section{DISCUSSION}

Traumatic diaphragmatic hernia occurs from both severe blunt trauma or penetrating traumas. Traumatic diaphragmatic hernia in acute cases are due to sudden increase in pleura-peritoneal pressure gradient.(4) TDH caused by penetrating injuries are potentially more dangerous in terms of possible obstruction and strangulation and infection in majority of cases that occurs in men and also involve (L) hemidiaphragm.(5) 
When the diaphragm is injured, the emerging events are unpredictable and dependent on various factors which may include site and site of defect, the relative position and negative pressures and subsequent stress and strains for this reason.(6) Carter et al divided symptomatology into 3 phases. First that immediately following accident. Second that of internalisation of organs. Third the phase of obstruction and strangulation. During the first phase, concomitant injuries may obscure that of diaphragm with injury which at that time may be relatively insignificant. In case of acute presentation, that is a sudden compression of thorax or abdomen producing bursting force resulting in a large rent causing huge herniation of bowel with immediate symptoms of respiratory and cardiac embarrassments, pain and shock.(7)

In case of subacute presentation, rent may be very large and so the abdominal contents pass freely between thoracic and abdominal cavity. There may be slow progression of collapse of lungs resulting in late onset of dyspnoea, whereas in delayed presentation the patient may not have immediate herniation of contents. It is because the diaphragmatic defect may be plugged with omentum at the time of injury and so setting the future in trouble. Since the margins of the defect in the diaphragm prevents from healing, the site is more vulnerable for future stress. And there may be slow herniation of contents due to the plug resulting in no respiratory or acute abdominal condition. And the patient may be presented few years to few days after injury and also only with non-specific abdominal pain. The correct diagnosis in diaphragmatic hernia is most readily made only when the injury is recent and tear is (L) sided with herniation of hollow organs.(2)

\section{CONCLUSION}

Traumatic diaphragmatic hernia can occur due to blunt injury abdomen or penetrating trauma or fall from height. Acute presentation is due to sudden collapse of lungs due to herniation of abdominal contents into chest causing ventilatory failure and patient may need immediate surgical correction. Whereas in case of subacute presentation, the symptoms may manifest few days to few weeks after injury, in which rent may be due to slowly enlarging or huge rent allowing contents to pass freely between thoracic abdominal cavity. Due to that there is slow collapse of ipsilateral lung, resulting the contralateral lung to compromise the ventilatory deficit. In case of delayed presentation, it may take 2 to 15 yrs. following trauma for the diagnosis and sometimes patient may present with non-specific abdominal complaints and accidently diagnosed with radiological studies at that time. There need not be signs of obstruction or gangrene formation in all cases.

\section{REFERENCES}

[1] Demuro JP. A delayed traumatic diaphragmatic hernia presenting with a bowel obstruction 20 years postinjury. J Clin Diapn Res 2013;7(4):736-8.

[2] Rashid F, Chakrabarty MM, Singh R, et al. A review on delayed presentation of diaphragmatic rupture. World Journal Emerg Surg 2009;4:32.

[3] Ball T, McCrorory R, Smith JO, et al. Traumatic diaphragmatic hernia: errors in diagnosis. AJR Am J Roentgenol 1982;138(4):633-7.

[4] Childress ME, Grimes OF. Immediate and remote sequelae in traumatic diaphragmatic hernia. Surg Gynecol Obstet 1961;113:573-84.

[5] Lomoschitz FM, Eisenhuber E, Linnau KF, et al. Imaging of Chest trauma: radiological patterns of injury and diagnostic algorithms. Eur J Radiol 2003;48(1):61-70.

[6] Carter BN, Guiseffi J, Felson B. Traumatic diaphragmatic hernia. AJR 1951;65:56-72.

[7] Reber PU, Schmied B, Seiler CA, et al. Missed diaphragmatic injuries and their long term sequelae. J Trauma 1998;44(1):183-8. 